\title{
Safety and Feasibility of Laparoscopic Surgery for Small Bowel Obstruction
}

\author{
Sang Chul Lee, M.D., Ph.D. \\ Department of Surgery, Daejeon St. Mary's Hospital, College of Medicine, The Catholic University of Korea, Daejeon, Korea
}

\author{
Corresponding author \\ Sang Chul Lee \\ Department of Surgery, Daejeon St. Mary's Hospital, College of Medicine, The Catholic University of Korea, 64 Daeheung-ro, Jung-gu, Daejeon 34943, Korea \\ Tel: +82-42-220-9114, Fax: +82-42-256-6807, E-mail: zambo9@catholic.ac.kr \\ ORCID: http://orcid.org/0000-0002-8681-7059
}

This is an Open Access article distributed under the terms of the Creative Commons Attribution Non-Commercial License (http:// creativecommons.org/licenses/by-nc/4.0/) which permits unrestricted non-commercial use, distribution, and reproduction in any medium, provided the original work is properly cited.

Copyright (C) 2018 The Journal of Minimally Invasive Surgery. All rights reserved.
Small bowel obstruction (SBO) is one of the most common causes of hospital admissions and emergent surgeries. Postoperative adhesion is the most common cause of SBO regardless of operative modalities. Laparotomy has been the standard treatment of choice for SBO in operative condition, but it can also be the frequent cause of postoperative adhesions. ${ }^{1}$ Experienced laparoscopic surgeons extended their applications and performed laparoscopy for SBO surgeries. ${ }^{2}$ Multiple studies and reports comparing laparoscopy and open surgery have revealed safety and feasibility of laparoscopic surgery and also postoperative short-term advantages of laparoscopic treatment for SBO including less postoperative pain, and faster recovery. ${ }^{3}$

Furthermore, single port laparoscopic surgery also is being used for the maximal benefits of minimally invasive surgery. Choi et al applied this procedure to all patients who were eligible for conventional laparoscopic surgeries and pointed out the ease of access, retrieval of specimens, and the relative simplicity of single port procedures beside of cosmetic results. ${ }^{4}$

In contrast, and generally, laparoscopic procedures for SBO are associated with a greater likelihood of intervention for bowel injury and/or repair and have the limited surgical working space because of bowel dilatation and the presence for intraperitoneal adhesions. ${ }^{5}$

In this study, time to water intake, time to soft diet, and postoperative hospital stay were significantly shorter in the laparoscopic surgery group. Propensity score matching analysis demonstrated that laparoscopic surgery showed quicker recovery and similar complication and recurrence rate. I agree authors' conclusion that laparoscopic surgery can be performed safely in patients with SBO.

\section{REFERENCES}

1) Ha GW, Lee MR, Kim JH. Adhesive small bowel obstruction after laparoscopic and open colorectal surgery: a systematic review and meta-analysis. Am J Surg 2016;212:527-536.

2) Mazzetti CH, Serinaldi F, Lebrun E, Lemaitre J. Early laparoscopic adhesiolysis for small bowel obstruction: retrospective study of main advantages. Surg Endosc 2018;32:2781-2792.

3) Nordin A, Freedman J. Laparoscopic versus open surgical management of small bowel obstruction: an analysis of clinical outcomes. Surg Endosc 2016;30:4454-4463.

4) Choi BJ, Kim SJ, Lee SC, Lee JI. Single-port laparoscopic treatment of small bowel obstruction. Am J Surg 2014;208:470-475.

5) Behman R, Nathens AB, Byrne JP, Mason S, Look Hong N, Karanicolas PJ. Laparoscopic Surgery for Adhesive Small Bowel Obstruction Is Associated With a Higher Risk of Bowel Injury: A Populationbased Analysis of 8584 Patients. Ann Surg 2017;266:489-498. 